\title{
Análise e modelagem gradual de um aplicativo para classificação de grãos soja, milho, feijão e sorgo
}

Analysis and gradual modeling of an Application for classification of soybeans, corn, beans and sorghum grains

Análisis y modelado gradual de una aplicación para clasificación de granos de soja, maíz, frijol y sorgo

Dionatan Pontes de Oliveira

ORCID: https://orcid.org/0000-0002-8352-8809 Instituto Federal de Educação, Ciência e Tecnologia Goiano, Brasil

E-mail: dionatan.oliveira@estudante.ifgoiano.edu.br

Guilherme Matos Ataides

ORCID: https://orcid.org/0000-0002-1833-6739 Instituto Federal de Educação, Ciência e Tecnologia Goiano, Brasil E-mail: guilhermedacatia132@gmail.com

Uender Carlos Barbosa

ORCID: https://orcid.org/0000-0003-1853-3967 Instituto Federal de Educação, Ciência e Tecnologia Goiano, Brasil

E-mail: uender.carlos@estudante.ifgoiano.edu.br

Alcídia Cristina Rodrigues Oliveira Bergland

ORCID: https://orcid.org/0000-0001-8348-5514 Instituto Federal de Educação, Ciência e Tecnologia Goiano, Brasil

E-mail: cristinabergalnd1@gmail.com

Daniela Cabral de Oliveira

ORCID: https://orcid.org/0000-0002-9647-933X Instituto Federal de Educação, Ciência e Tecnologia Goiano, Brasil E-mail: danielacaboliveira@gmail.com

Daniel Emanuel Cabral de Oliveira

ORCID: https://orcid.org/0000-0002-3824-994X Instituto Federal de Educação, Ciência e Tecnologia Goiano, Brasil E-mail: daniel.oliveira@ifgoiano.edu.br

Maria Gláucia Dourado Furquim

ORCID: https://orcid.org/0000-0001-7823-9546 Instituto Federal de Educação, Ciência e Tecnologia Goiano, Brasil E-mail: maria.furquim@ifgoiano.edu.br

José Carlos de Sousa Júnior

ORCID: https://orcid.org/0000-0003-2578-8140 Instituto Federal de Educação, Ciência e Tecnologia Goiano, Brasil E-mail: josecarlos.junior@ifgoiano.edu.br

\section{Resumo}

Neste projeto objetivou-se detalhar a análise e modelagem gradual do desenvolvimento de um aplicativo para classificação de grãos soja, milho, sorgo e feijão, tendo como finalidade disponibilizar ao produtor uma ferramenta que possibilite monitorar o processo de classificação de grãos soja, milho, sorgo e feijão. Ao produtor, é delegado a finalidade de inserir dados na ferramenta disponibilizada, da qual processa o acompanhamento e o monitoramento do processo de classificação de grãos, de modo que seja possível por parte do produtor a confrontação dos resultados obtidos pelo aplicativo, da geração dos laudos técnicos, para se comparar com o da organização recebedora. Desta maneira, objetiva-se apurar em tempo real a classificação dos grãos voltado ao produtor desejada, no que se abrange a soja, milho, feijão e sorgo, conforme os padrões legalmente instituídos por normativas (feijão 12/2008, milho 60/2011, soja 11/2007 e sorgo portaria 268/1984) do Ministério da Agricultura, Pecuária e Abastecimento (MAPA) e também baseado na literatura especializada. No ato da comercialização, os resultados do aplicativo referente a base de dados geral e específica por lote que é gerada, auxiliando ao final do processo de classificação de grãos na redução de disparidades e prejuízos do lote.

Palavras-chave: Aplicativo; Classificação de grãos; Produtor.

\section{Abstract}

This project aimed to detail the analysis and gradual modeling of the development of an Application for classification of soybeans, corn, sorghum and beans, with the purpose of providing the producer with a tool that allows monitoring 
the process of classification of soybeans, corn, sorghum grains and bean. The producer is delegated the purpose of inserting data into the available tool, which processes the monitoring and monitoring of the grain classification process, so that it is possible for the producer to confront the results obtained by the Application, the generation of the reports to compare with that of the receiving organization. In this way, the objective is to ascertain in real time the classification of grains aimed at the desired producer, with regard to soy, corn, beans and sorghum, according to the standards legally instituted by regulations (beans 12/2008, corn 60/2011, soybean 11/2007 and sorghum ordinance 268/1984) of the Ministry of Agriculture, Livestock and Supply (MAPA) and also based on specialized literature. In the act of commercialization, the results of the Application referring to the general and specific database per lot that is generated, assisting at the end of the grain classification process in the reduction of disparities and losses of the lot.

Keywords: Application; Grain classification; Producer.

\section{Resumen}

Este proyecto tuvo como objetivo detallar el análisis y modelado gradual del desarrollo de una aplicación para clasificación de soja, maíz, sorgo y frijol, con el propósito de brindar al productor una herramienta que permita monitorear el proceso de clasificación de soja, maíz, sorgo. granos y frijoles. Se delega al productor la finalidad de insertar los datos en la herramienta proporcionada, la cual procesa el seguimiento y seguimiento del proceso de clasificación de granos, de manera que le sea posible al productor confrontar los resultados obtenidos por la aplicación, generando los informes para comparar con ese de la organización receptora. De esta forma, el objetivo es conocer en tiempo real la clasificación de granos dirigida al productor deseado, en lo que se refiere a soja, maíz, frijol y sorgo, de acuerdo con las normas legalmente instituidas por reglamento (frijoles 12/2008, maíz 60 / 2011, soja 11/2007 y sorgo ordenanza 268/1984) del Ministerio de Agricultura, Ganadería y Abastecimiento (MAPA) y también en base a literatura especializada. En el acto de comercialización, los resultados de la solicitud se refieren a la base de datos general y específica por lote que se genera, ayudando al final del proceso de clasificación de granos en la reducción de disparidades y pérdidas del lote.

Palabras clave: Aplicación; Clasificación de soja; Productor.

\section{Introdução}

A classificação de grãos compreende uma etapa de caracterização do produto no ato da comercialização, tendo por base análises específicas e por comparação entre amostra analisada e padrões oficiais aprovados pelo Ministério da Agricultura, Pecuária e Abastecimento (MAPA). Segundo Alencar et al., (2009) a qualidade dos grãos é um padrão bastante relevante para comercialização e processamento, podendo afetar o valor do produto.

Atualmente a classificação de grãos é regulamentada de acordo com as legislações e normas estabelecidas pelo MAPA, o qual designa regras de classificação para cada grão. O processo de classificação de grãos abrange as seguintes etapas: amostragem, homogeneização, quarteamento, determinação de matéria estranha e impureza (MEI), determinação do teor de água, determinação de Grupo/ Classe/ Tipo de grãos (soja, milho, feijão e sorgo) e emissão de laudo. Após realizar todas as etapas do processo de classificação de grãos é comparado o grupo, a classe e o tipo de cada grão produzido ao que é considerado padrão. Através dessas avaliações são aplicados descontos nos lotes de grãos que serão vendidos (Sampaio, 2015).

As principais vantagens da etapa de classificação de grãos é permitir o uso de uma linguagem comercial padronizada e convencionada em todo país, promover a garantia da classificação de grãos por meio de laudo ou do certificado de classificação, possibilitar à organização um preço justo para o grão de acordo com as características favoráveis ou desfavoráveis, facilitar a comparação dos preços dos grãos em diferentes mercados e possibilitar que os fornecedores dos grãos de origem vegetal padronizado realizem o controle interno da qualidade (Knabben \& Costa, 2012).

Dentre as desvantagens encontradas pelo produtor de grãos no Brasil destaca a diferença do teor de umidade e impurezas detectados pelas unidades armazenadoras de grãos em detrimento do que é apurado pelo produtor. Além disso tais disparidades são encontradas também de uma organização para a outra, o que acarreta altos prejuízos (Silvestre, 2017).

Neste sentido, emerge a tecnologia da informação nas práticas agrícolas possibilitando grandes avanços, especialmente através de ferramentas como aplicativos (Apps) agrícolas, os quais propiciam uma grande diversidade de funções e serviços para dispositivos móveis. Estes aplicativos auxiliam no processamento de um significativo volume de dados informatizados necessários para ajudar os agricultores e técnicos na tomada de decisões que otimizam os rendimentos. 
Os aplicativos agrícolas tornam a gestão das atividades relativas à agricultura e a pecuária eficientes ao promover o acesso os dados tornando-as acessível e compartilhável, além uso imediato em qualquer local que se esteja. No segmento de classificação de grãos existem poucas opções de aplicativos que realizam a classificação de grãos no mercado sendo eles corporativos, constituindo o presente estudo na descrição das atividades relativas ao desenvolvimento de um aplicativo destinado a classificação de grãos.

\section{Revisão de literatura}

\section{Aspectos gerais sobre a classificação de grãos no Brasil: conceitos e legislação vigente}

A classificação de grãos compreende em procedimento operacional que apura a qualidade dos produtos comercializados pelo produtor, consoante às especificações contratadas e a legislação vigente. Possui a Lei a n 9.972 , de 25 de maio de 2000, regulamentada pelo Decreto $\mathrm{n}^{\circ}$ 6.268, de 22 de novembro de 2007 como base para a estrutura legal que determina como obrigatório a classificação dos produtos de origem vegetal, visando assegurar a qualidade dos produtos destinados diretamente à alimentação humana, bem como seus subprodutos e resíduos de valor econômico; operações de compra e venda do poder público; e nos portos, aeroportos e postos de fronteira, quando da importação (Abiove, 2019, p. 7). Ademais, promove maior transparência no processo de comercialização, reduzindo as disparidades entre o que está sendo vendido e o que está sendo entregue no ato da compra. Portanto, a classificação de grãos está diretamente associada ao atendimento de padrões estabelecidos para cada tipo de cultura a ser analisada, conforme o conjunto de parâmetros que determinam características extrínsecas e intrínsecas do produto.

De acordo com o Senar (2017, p. 10). “A padronização é o estabelecimento de modelo, do tipo físico, ou de caracteres descritos acerca dos produtos vegetais, considerando a identidade, o emprego, a forma, a cor, o peso, o tamanho, a apresentação e a qualidade para fins de classificação vegetal. Padronizar é agir segundo um modelo ou na conformidade de um padrão". Sendo que a partir do conjunto de especificações que compõem o padrão, são definidos os parâmetros qualiquantitativo tolerado nas amostras analisadas de cada cultura, sendo os aspectos qualitativos representados pelos defeitos e os quantitativos a tolerância em percentuais destes defeitos. "O padrão poderá sofrer alterações e revisões, de forma a adequá-lo às evoluções tecnológicas do setor agrícola, ou às preferências do consumidor, aos hábitos culturais e aos processos da utilização nas diferentes regiões do país, mediante portarias específicas do Mapa” (Senar, 2017, p. 10).

Em termos gerais, a instituição de critérios legais que parametriza o processo de classificação de produto vegetal, objetiva assegurar a qualidade do produto no ato da comercialização mediante análise e comparação de amostra coletada, com os padrões definidos e oficialmente instituídos pelo Governo Federal por meio do Ministério da Agricultura, Pecuária e Abastecimento - MAPA. Todavia, cabe mencionar que a classificação pode ser: Oficial, ou seja, segue as normas de segurança alimentar para oferecer produtos seguros aos consumidores finais; e, Comercial - cujos parâmetros pode se adequar as necessidades de cada empresa (Senar, 2017, p. 12).

Assim sendo, a classificação do feijão segue o que prevê a Instrução Normativa - IN no 12 , de 28 de março de 2008, que define o enquadramento do produto em Grupo, ou seja, a espécie botânica; Classe, que consiste na identificação do feijão conforme a coloração do tegumento (película) do grão que podem ser: Preto, Branco, Cores ou Misturado; e o Tipo, que referese aos atributos do produto, considerando a relação dos limites máximos de defeitos legalmente aceitos em comparação com os presentes na amostra. Os defeitos graves são: mofado, ardido, germinado, carunchado e atacado por lagartas das vagens; e os defeitos leves são: amassados, danificados, partido e quebrado e imaturo (Knabben \& Costa, 2012).

A IN nº 11/2007 estabelece como disposições gerais no “Art. $1^{\circ} \mathrm{O}$ presente Regulamento Técnico tem por objetivo definir o padrão oficial de classificação da soja, considerando os seus requisitos de identidade e qualidade intrínseca e extrínseca, de amostragem e de marcação ou rotulagem". Ademais, este regulamento se aplica ao produto soja em grãos 
provenientes da espécie botânica Glycine max (L) Merrill; cujo procedimento inicial é a inspeção visual para averiguar se o produto é ou não passível de classificação, no qual o estado de conservação do produto (ácido e/ou azedo) e a presença de sementes tóxicas e animais (vivos ou mortos), bem como o percentual de defeitos maiores que 12\% (soja tipo I) e 40\% (tipo II) incorre na reprovação da carga. Posteriormente, são realizadas as atividades padrão na classificação, como coleta e homogeneização da amostra, sendo que "A obtenção da amostra (ou amostragem) deve ocorrer de acordo com o estabelecido no art. $9^{\circ}$ do Decreto $\mathrm{n}^{\circ}$ 3.664/00, que fixa a terminologia, os critérios e os procedimentos necessários" (Senar, 2017, p. 25). Em seguida são realizados o quarteamento, a determinação de matéria estranha e impureza - MEI, a determinação do teor de umidade, os procedimentos analíticos para o enquadramento do grão (grupo, classe, tipo, identificação de defeitos e limites toleráveis) e a emissão do laudo. Ainda segundo a IN n ${ }^{\circ} 11$, a soja é classificada em Grupo I, quando destinada ao consumo in natura e Grupo II, quando direcionada a outros fins, como esmagamento para produção de óleo e farelo ou alimentação animal, sendo também classificada em duas classes, em decorrência da coloração do grão: amarela ou misturada.

Por sua vez, a IN n ${ }^{\circ}$ 60/2011 "Define o padrão oficial de classificação do milho, considerando seus requisitos de identidade e qualidade, a amostragem, o modo de apresentação e a marcação ou rotulagem, nos aspectos referentes à classificação do produto" (MAPA, 2011). O regulamento se aplica aos grãos provenientes da espécie Zea mays L., sendo o milho pipoca, sujeito à determinação específica. O milho será classificado em Grupos, considerando a consistência e o formato do grão que podem ser: duro, dentado, semiduro ou misturado. Segundo a coloração do grão é definido a Classe que se classifica em: amarela, branca, cores e misturada. O milho será classificado em três Tipos (1,2,3), conforme a sua qualidade e os limites máximos de tolerâncias, podendo também ser definido como Fora de Tipo ou Desclassificado. Quanto aos defeitos do grão milho, eles são divididos em defeitos graves os quais podem ser ardidos ou mofados e que comprometem a qualidade, aparência e possibilidade de uso do grão; e defeitos leves: fermentados, germinados, carunchados, choco ou imaturo, gessados e quebrados. "Geralmente, nas classificações comerciais, o milho mais comercializado entre os produtores rurais e as empresas compradoras de grãos é o chamado (tipo 2). Existem limites de tolerância para essa negociação, podendo sofrer alterações" (Senar, 2017, p. 78).

A Portaria n 268/1984, normatiza as características de identidade, qualidade, embalagem e apresentação do sorgo que se destina à comercialização interna, a qual define o produto sorgo, como sendo os grãos provenientes da espécie Sorghum bicolor, (L) Moench. O sorgo será classificado consoante sua coloração e sua qualidade em classes (Branco, Amarelo, Vermelho, Castanho e Mesclado) e quatro tipos $(1,2,3,4)$ a partir dos limites máximos de tolerância de defeitos/tipo de produto independentemente da classe à qual se enquadra.

\section{Material e métodos}

A elaboração deste trabalho envolveu o gerenciamento dos processos de levantamento de requisitos, análise e modelagem, escopo, qualidade, tempo e risco, segundo designado pelo Guia Project Management Body of Knowledge (PMBOK®). Segundo Justo (2018) o diagrama de Estrutura Analítica do Projeto (EAP), é um desdobramento hierárquico do trabalho do projeto em parcelas menores, foi guia para elucidação e refinamento do escopo. Em análise, a Figura 1 ilustra a EAP em forma de organograma, de maneira a demonstrar as atividades de cada etapa do projeto. 
Figura 1 - Estrutura Analítica do Projeto (EAP).

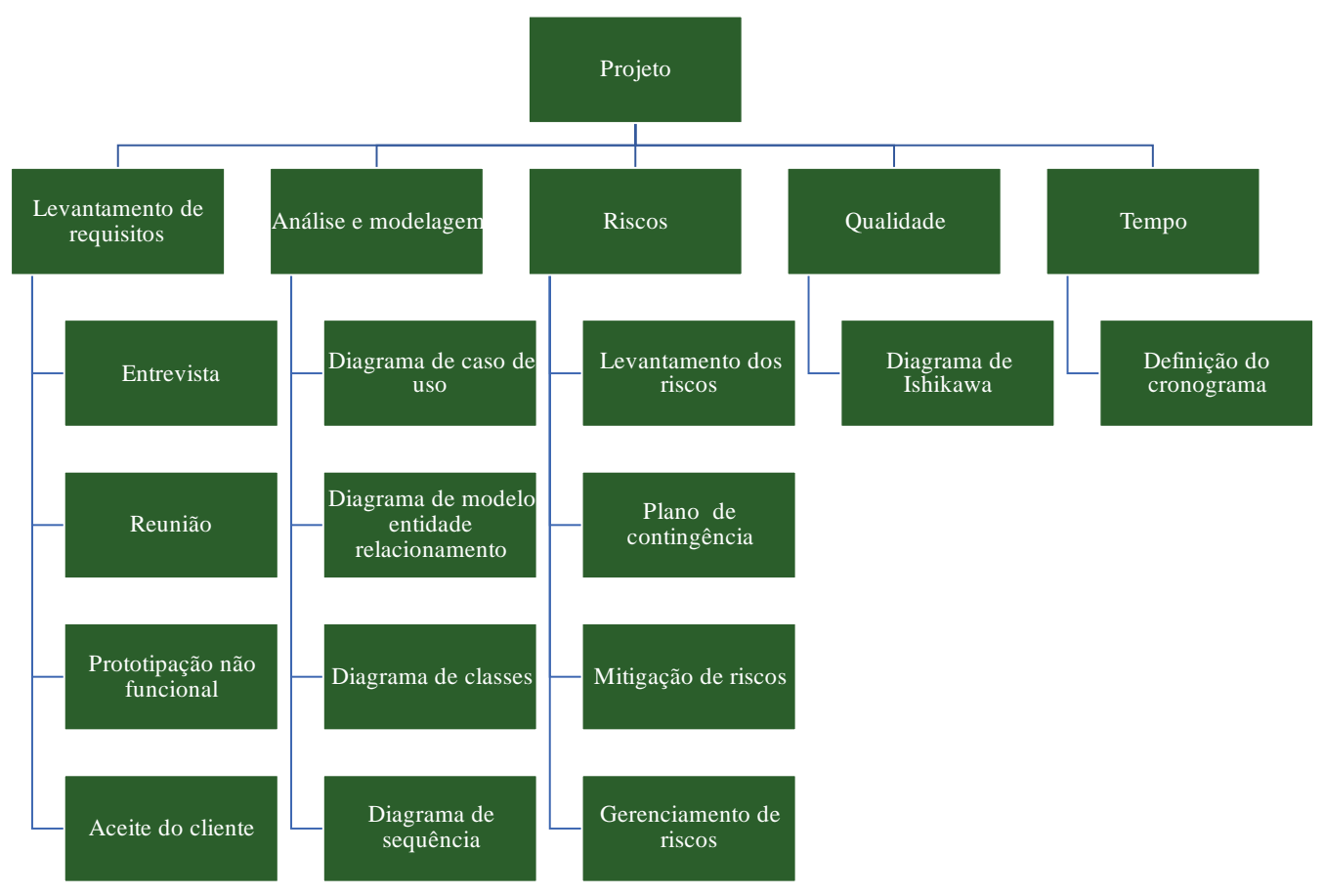

Fonte: Elaborado pelos atores (2020).

Na primeira etapa do projeto para a elicitação de requisitos foi realizado o acompanhando das atividades de recebimento e armazenamento de soja, em uma unidade armazenadora de grãos na microrregião de Iporá em Goiás. A elicitação de requisitos foi dividida em sub etapas: Entrevistas; Reuniões; Prototipação não funcional e Aceite do cliente. Segundo Chaves (2017) a técnica entrevista permite que entrevistador e entrevistado possam ter um diálogo de maneira mais completa. Posterior a entrevista foram realizadas reuniões para que houvesse a validação das alterações e dos requisitos funcionais e não-funcionais, de maneira a verificar se a aplicação satisfaz os anseios do cliente.

Após definida a necessidade do cliente, o modelo de prototipagem foi utilizado como metodologia para determinar o ciclo de vida do software. Desta forma foram criados esboços iniciais das telas relativas a cada funcionalidade da aplicação. A partir da aprovação do cliente, uma nova versão do protótipo foi obtida. Tal processo une ações de planejamento-averiguaçãoprática, que fomentam o aperfeiçoamento da aplicação, até se resultar no produto final (Silvestri, 2017). A Figura 2, ilustra a visualização das modificações no protótipo, na criação de cada novo incremento/versão do aplicativo: 
Figura 2. Capturas de tela. Evolução do Protótipo.

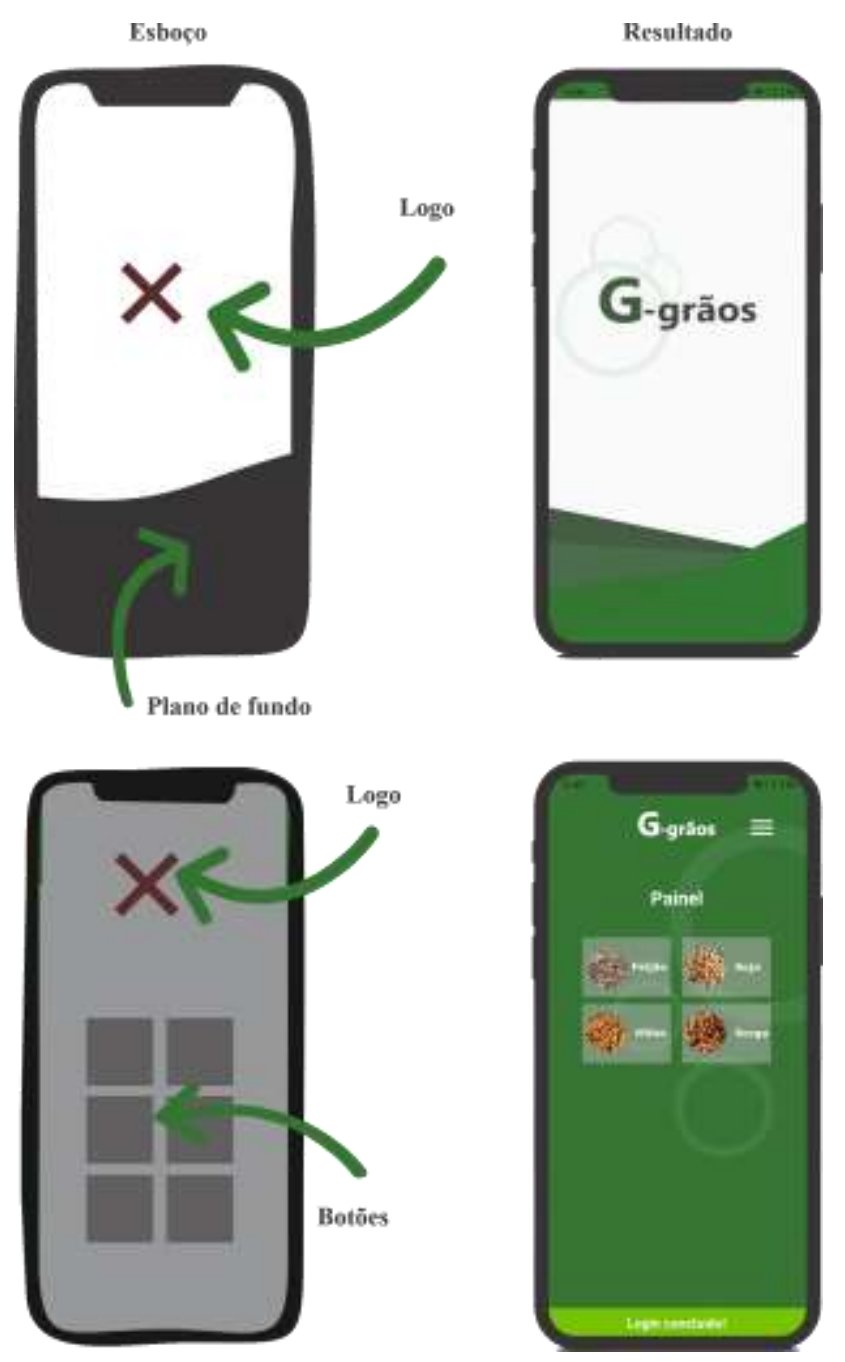

Fonte: Elaborado pelos atores (2020).

A presente proposta metodologicamente, possui natureza qualitativa, com objetivos exploratórios e descritivos acerca de temas inerentes aos recursos tecnológicos e de informações aplicáveis no meio rural, bem como o entendimento sobre as bases legais que regulamentam a classificação de grãos no Brasil, obtido a partir de revisão bibliográfica.

\section{Resultados e discussões}

$\mathrm{O}$ processo de desenvolvimento de software, compreende um conjunto de etapas que permita uma visão geral e antecipada do projeto através de uma linguagem padronizada, de modo a possibilitar ajustes e alterações antes mesmo da implementação. Neste sentido, projetar um sistema requer o levantamento e documentação do sistema em si e da comunicação entre as partes, considerando uma relação de causa e efeito no qual as tarefas a serem realizadas é entendido como entradas e o produto destas tarefas específicas a saída (Gonçalves \& Cortés, 2015). Neste contexto, a compreensão de como ocorre o levantamento de requisitos é fundamental a concepção das fases de análise e desenvolvimento do projeto, sendo descritos a seguir as etapas inerentes ao desenvolvimento do aplicativo G-Grãos.

\section{Escopo}

O escopo deste trabalho envolveu a análise e a modelagem de um aplicativo desenvolvido para a plataforma Android para auxiliar na classificação dos grãos soja, milho, feijão e sorgo, conforme os padrões legalmente instituídos por normativas 
(soja 11/2007, milho 60/2011, feijão 12/2008 e sorgo portaria 268/1984) do Ministério da Agricultura, Pecuária e Abastecimento (MAPA).

Por meio do aplicativo o produtor é capaz de manter a classificação de grãos, calcular o desconto sobre a carga do caminhão, manter a amostragem dos grãos e calcular a classe, grupo e tipo do grão. $\mathrm{O}$ usuário poderá realizar estas funções se cadastrando no sistema. Além disso terá um relatório das classificações e descontos realizados podendo usá-lo para confrontar seus dados no ato da comercialização de grãos com os das empresas armazenadoras de grãos, reduzindo possíveis disparidades e prejuízos no lote. Desta maneira, objetiva-se apurar em tempo real a classificação dos grãos. Como restrições, não será possível a comercialização de grãos através do aplicativo.

\section{Riscos}

O projeto possui riscos para sua realização na esfera organizacional, de gerenciamento do projeto, técnico ou externo. Este planejamento pode ser sucessível a entraves, desafios e empecilhos, como: a) Impossibilidade/dificuldade de locomoção dos integrantes até o ponto de encontro/reunião; b) Tempo insuficiente, se houver imprevisto, o que impacta no gasto de tempo, extrapolando o cronograma, e assim, pode impedir a execução da etapa seguinte; c) Exposição ao risco de Saúde, especialmente por causa da pandemia do COVID-19 e outros; d) A possibilidade de atividades planejadas não serem cumpridas, se houver desistência ou não-cumprimento de algum integrante; e) Resistência do cliente em contribuir e participar, de forma flexível e aberta, do processo de desenvolvimento de software, seja pela falta de motivação, comunicação, interesse ou indisponibilidade de tempo; f) Desistência do projeto pelo cliente. Para uma melhor gestão, os riscos foram priorizados de acordo com o Quadro 1:

Quadro 1. Matriz de Probabilidade x Impacto.

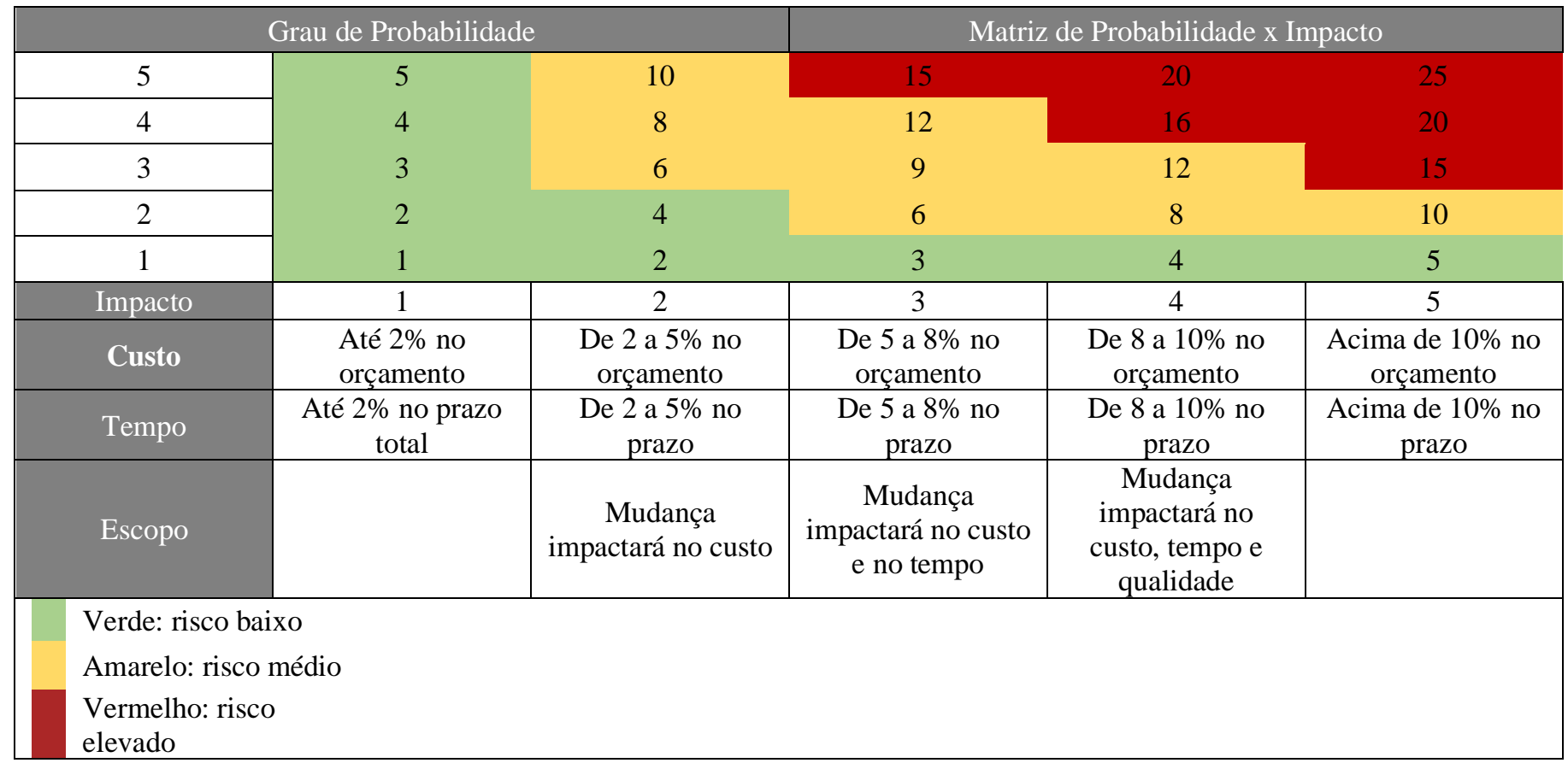

Fonte: Escritório de Projetos. Modificado pelos atores (2020)

\section{Qualidade}

A Figura 3, o Diagrama de Ishikawa também chamado Diagrama de Espinha de Peixe ou Diagrama de Causa e Efeito, é um procedimento de qualidade que analisa a totalidade dos fatores que estão envolvidos na execução do processo, ou seja, auxilia no levantamento das causas-raízes de um problema (Bastiani \& Martins, 2018). 
Figura 3. Diagrama de Ishikawa.

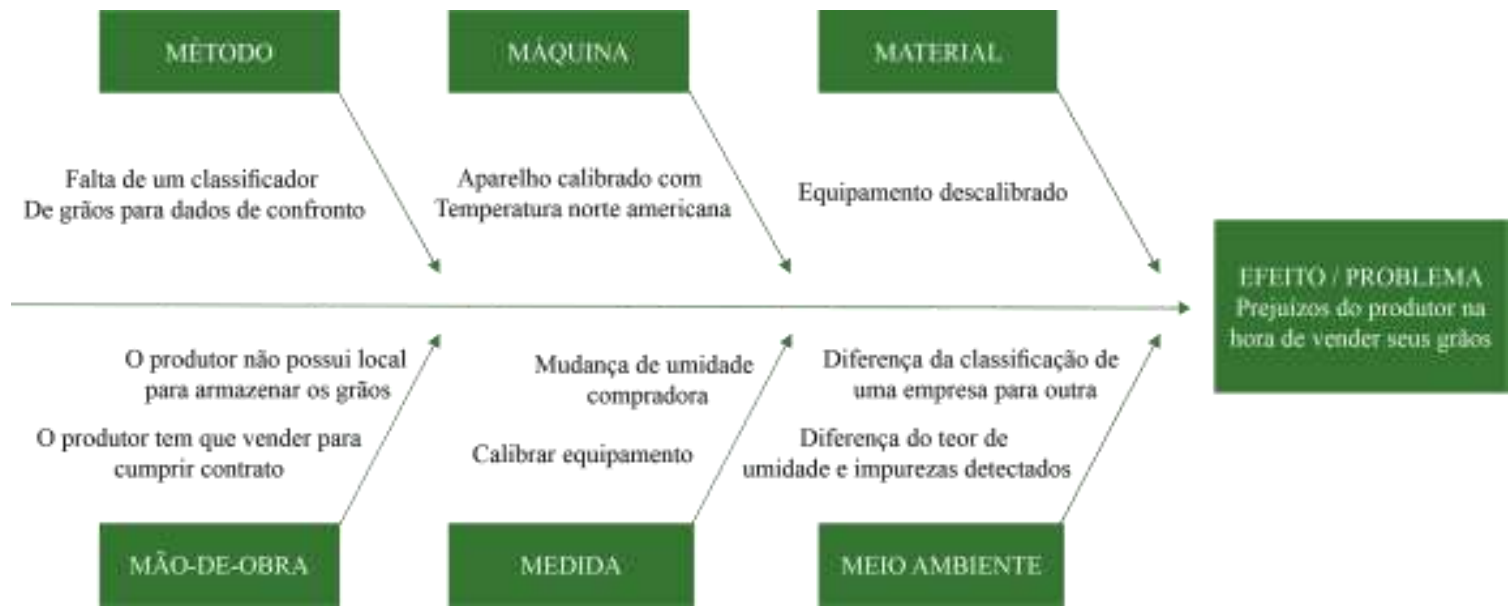

Fonte: Elaborado pelos atores (2020).

O diagrama de causa e efeito retrata as causas que os produtores de grãos enfrentam no processo de classificação de soja, feijão, milho e sorgo demonstrando o efeito, ou seja, os potenciais prejuízos do produtor no momento de comercializar os grãos.

\section{Tempo}

Inicialmente, para o desenvolvimento do projeto proposto, criou-se um projeto de extensão com a proposta de desenvolver um aplicativo para plataforma Android, tendo como finalidade disponibilizar ao produtor rural uma ferramenta que possibilitasse monitorar o processo de classificação de grãos (soja, feijão, milho e sorgo), podendo assim confrontar os resultados apurados pelo aplicativo com o da empresa armazenadora de grãos. Por intermédio do documento criado foi possível demonstrar o funcionamento do cenário atual, verificar a importância do mesmo e definir as metas a serem realizadas, conforme demonstrado no cronograma representado na Figura 4, no qual foi utilizada a ferramenta de projeto Gantt Project.

Figura 4. Cronograma desenvolvido com Gantt Project.

\begin{tabular}{|c|c|c|c|c|}
\hline & & Nome & Data inicial & Data final \\
\hline & - 1 & Projeto G-Gráos aplica. & $11 / 05 / 20$ & $31 / 12 / 20$ \\
\hline & $=1$ & Desenvolvimeto do $\mathrm{cr}$ & $11 / 05 / 20$ & $25 / 05 / 20$ \\
\hline & $\cdot$ & Criaçalo da Estrutura A. & $26 / 05 / 20$ & $22 / 06 / 20$ \\
\hline 日 & + & Levantamento de Req_- & $25 / 06 / 20$ & $21 / 09 / 20$ \\
\hline & & - Entrevista & $25 / 06 / 20$ & $25,06 / 20$ \\
\hline & & - Reunioes & $22 / 07 / 20$ & $22,07 / 20$ \\
\hline & & " Prototipaç̧o ndo- & $20 / 08 / 20$ & $20 / 08 / 20$ \\
\hline & & - Aceite do cliente & $21 / 09 / 20$ & $21,09 / 20$ \\
\hline \multirow[t]{2}{*}{ 日 } & $\cdot$ & Definição dos riscos & $30,09 / 20$ & $15 / 10 / 20$ \\
\hline & & - Matriz de Probabili. & $30,09 / 20$ & $15 / 10 / 20$ \\
\hline \multirow[t]{2}{*}{ B } & $\cdot$ & Definiçâo da Qualídade & $16 / 10 / 20$ & $30 / 10 / 20$ \\
\hline & & " Diagrama de ishik. & $16 / 10 / 20$ & $30 / 10 / 20$ \\
\hline \multirow[t]{5}{*}{ 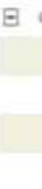 } & $\cdot 1$ & Modelagem do Sistema & $09 / 11 / 20$ & $31 / 12 / 20$ \\
\hline & & - Diagrama de caso ... & $09 / 11 / 20$ & $20 / 11 / 20$ \\
\hline & & - Diagrama Entidade. & $23 / 11 / 20$ & $01 / 12 / 20$ \\
\hline & & - Diagrama de Classe & $02 / 12 / 20$ & $16 / 12 / 20$ \\
\hline & & - Diagrama de Sequ & $17 / 12 / 20$ & $31 / 12 / 20$ \\
\hline
\end{tabular}

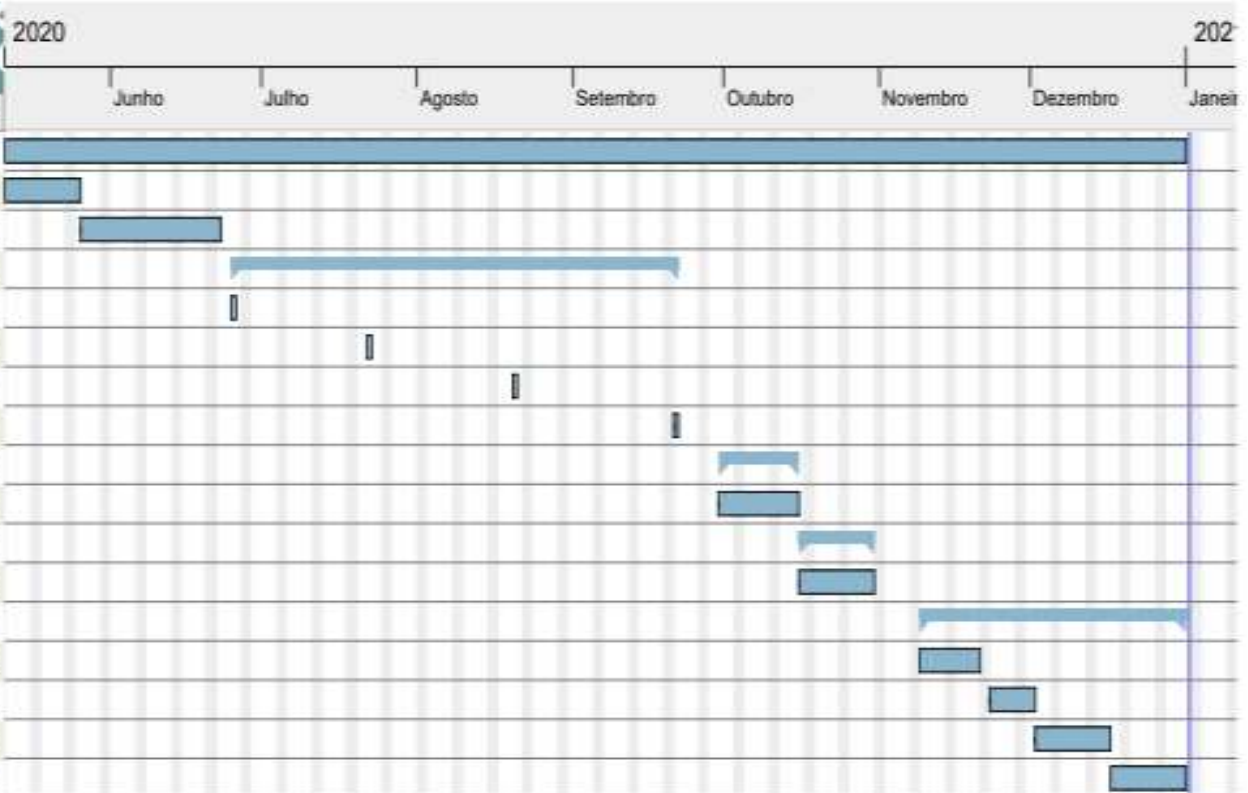

Fonte: Elaborado pelos atores (2020). 


\section{Análise e modelagem}

Conforme linguagem de modelagem de software (UML), o projeto foi modelado e desenvolvido para demonstrar a visualização, especificação, construção e documentação dos artefatos do projeto. Sendo assim, 4 (quatro) diagramas (caso de uso, entidade relacionamento, classe e sequência) foram elaborados para auxiliar o desenvolvedor nas tarefas de estruturar, abstrair e definir objetos e seus atributos, bem como para delimitar/criar as funcionalidades, em cada uso.

\section{Diagrama de casos de uso}

No desenvolvimento do software há a necessidade de constatar quem serão os usuários do sistema, ou seja, os atores, e como eles irão usá-lo(funcionalidades), para isso utiliza-se a técnica denominada Caso de Uso, que possibilita o levantamento dos requisitos do sistema através do seu uso (Guedes, 2018).

A Figura 5, é a representação visual do Diagrama de caso de uso, por meio dela pode-se observar o usuário(ator) e suas respectivas funcionalidades. No caso de uso efetuar login, o usuário cadastrado pode logar no sistema. No caso de uso manter produtor, o aplicativo possibilita que o usuário realize seu cadastro e altere seus dados. No caso de uso manter amostra, o usuário cadastra, busca, edita e deleta amostras dos grãos soja, milho, feijão ou sorgo. No caso de uso manter classificação, o usuário cadastra, busca e edita uma determinada classificação pertencente a uma amostra (soja, milho, feijão ou sorgo) já cadastrada. No caso de uso calcular descontos o usuário calcula os descontos incidentes sobre a carga de grãos (soja, milho, feijão ou sorgo) do caminhão. No caso da função calcular classe, grupo e tipo de grão, o usuário calcula em qual classe, grupo e tipo o grão pertence, conforme os atributos determinantes de cada grão (soja, milho, feijão ou sorgo).

Figura 5. Diagrama de caso de uso.

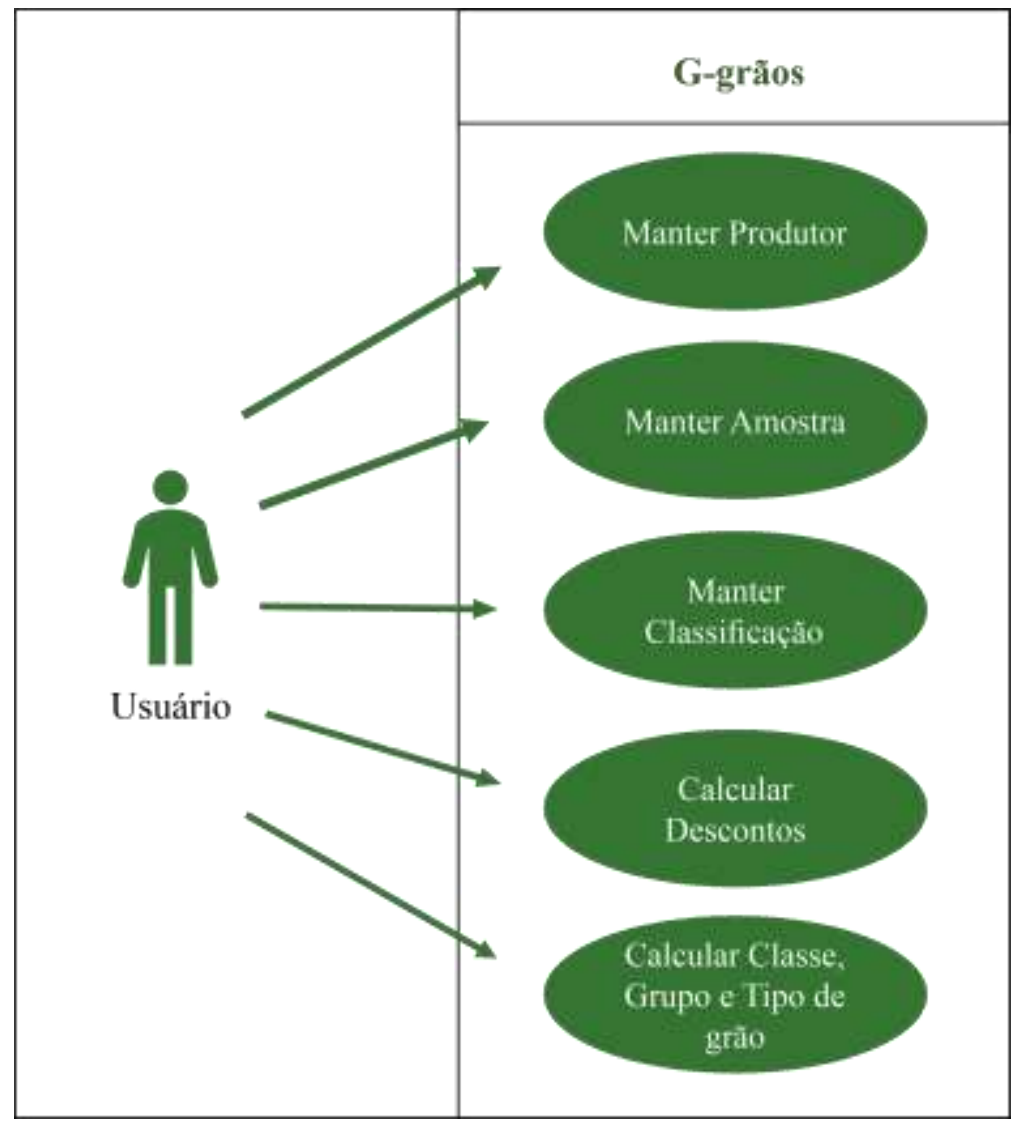

Fonte: Elaborado pelos atores (2020). 
Segundo Gonçalves \& Cortés (2015, p. 47) "Este é um diagrama comportamental utilizado nas fases iniciais do projeto, portanto seu principal objetivo é explicitar de forma macro (sem detalhes) os requisitos funcionais de um sistema, partindo do ponto de vista do usuário".

\section{Diagramas de classe}

Dos diagramas da UML o Diagrama de classe é considerado um dos mais importantes, pois possibilita a visualização do software representado em forma de classes com seus respectivos atributos e métodos. Tais classes por sua vez possuem relacionamentos e trocam informações entre as demais (Guedes, 2018). O diagrama de classe esboçado na Figura 6 permite a visualização das classes que integram o sistema, seguidas de seus métodos, atributos e relacionamentos.

Figura 6. Diagrama de classe.

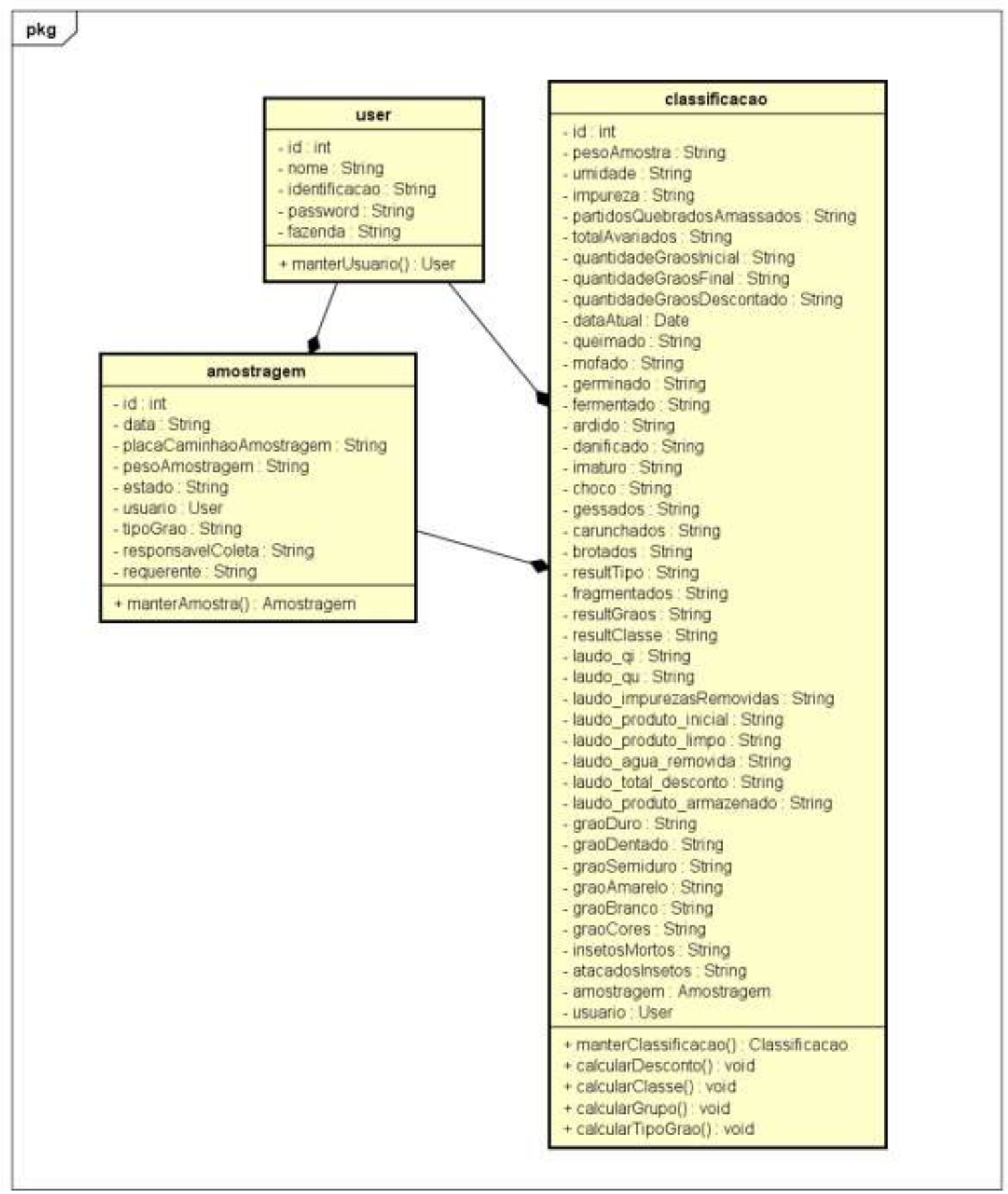

Fonte: Elaborado pelos atores (2020). 


\section{Diagrama de entidades relacionamento}

Segundo Generoso (2019) “A modelagem de um banco de dados trata-se de uma representação das necessidades dos sistemas e do que será armazenado". O diagrama de Entidades Relacionamento representa elementos do mundo real em forma de tabelas, com seus respectivos atributos, conforme apresentado na Figura 7.

Figura 7. Diagrama de entidades relacionamento.

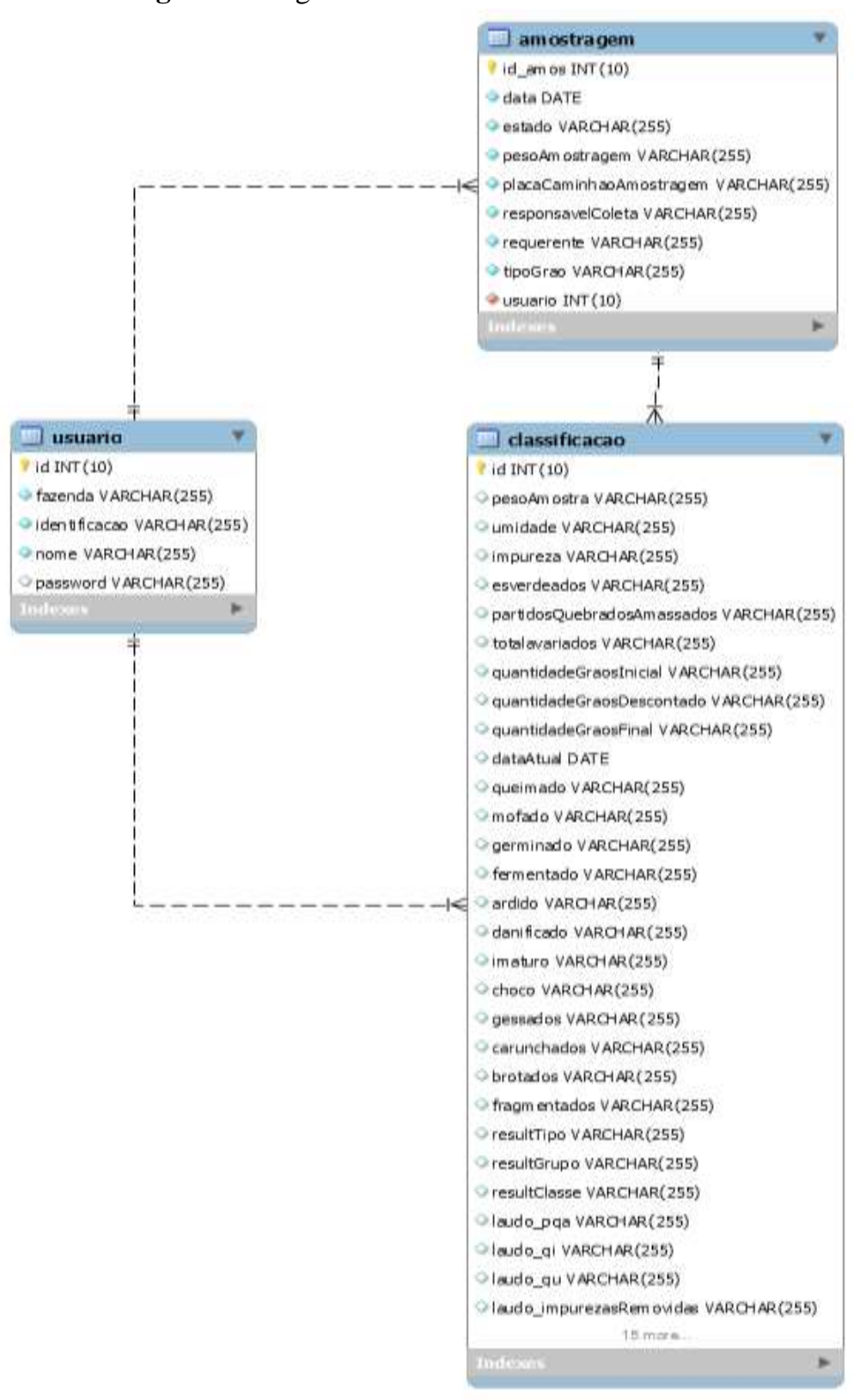

Fonte: Elaborado pelos atores (2020).

\section{Diagrama de sequência}

Conforme Guedes (2018), “O diagrama de sequência é um diagrama comportamental que se preocupa com a ordem temporal em que as mensagens são trocadas entre os objetos envolvidos em um determinado processo”. Assim, tal diagrama detecta o evento gerador do processo a ser modelado, o ator(usuário) responsável pelo evento, além de definir como todo o 
processo deve ser conduzido e concluído através de mensagens trocadas entre os objetos, conforme apresenta o Diagrama de sequência manter amostra na Figura 8.

Figura 8. Diagrama de sequência.

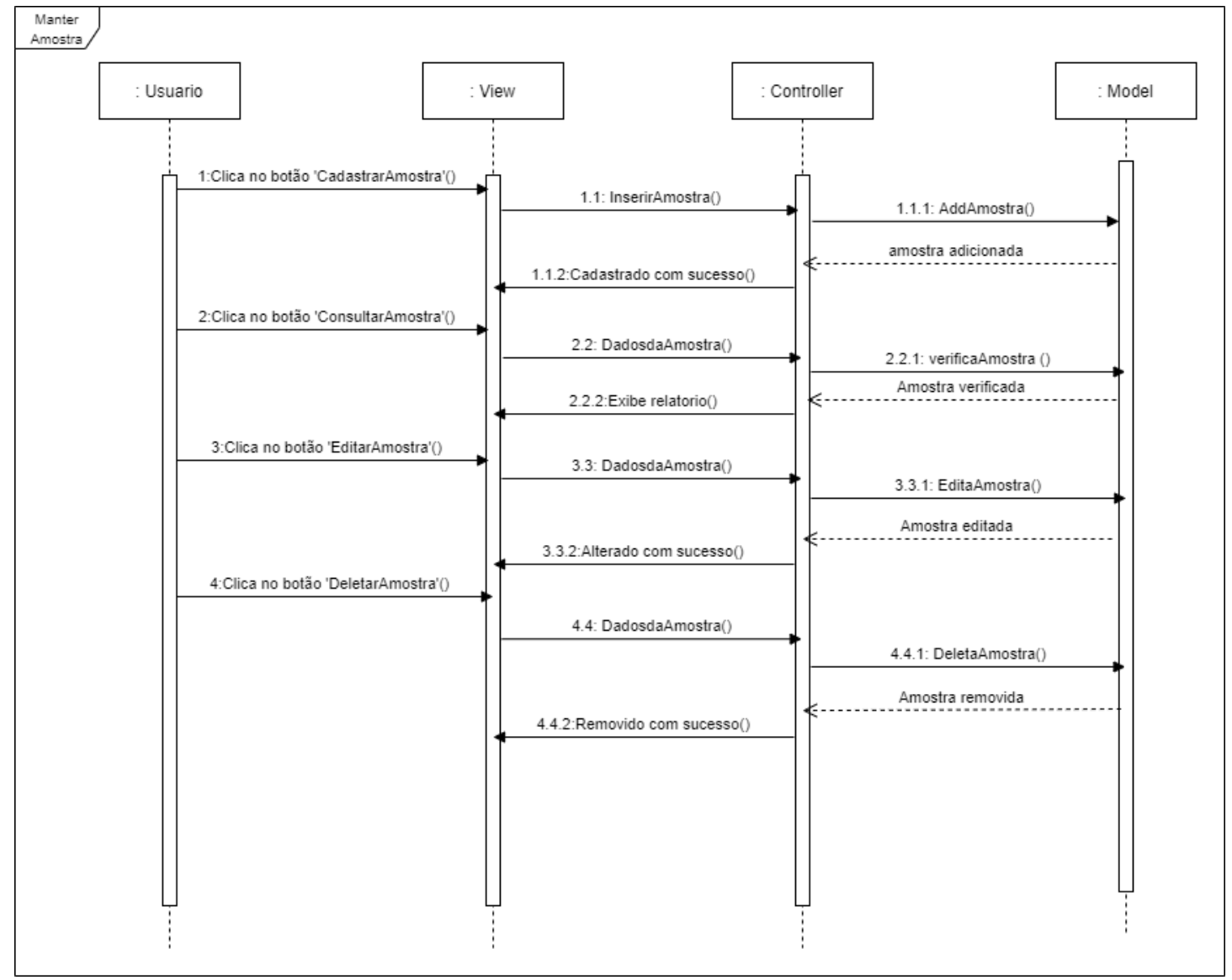

Fonte: Elaborado pelos atores (2020).

O aplicativo G-Grãos conforme modelado, possibilita a classificação de grãos de soja, milho, sorgo e feijão por parte do produtor no ato da comercialização dos grãos, mediante a inclusão dos dados da amostra, gerando um laudo classificativo próprio. Como anteriormente descrito, optou-se por uma interface simples e intuitiva, projetada considerando a familiaridade do usuário com os ícones utilizados, ao mesmo tempo em que demanda pouco espaço de armazenamento por usar pouca memória RAM, além da possibilidade de acesso gratuito pelo público interessado.

Cabe destacar que, o App considera os parâmetros oficialmente estabelecidos pelo MAPA para a classificação dos grãos contemplados no sistema, pela sua abrangência como critério de classificação, embora haja na classificação comercial, normas definidas pelas empresas compradoras que possam variar de uma empresa para outra ou entre regiões diferentes, contudo, desde que regulamentado. Assim, para o produtor a classificação promove maior transparência na recepção dos seus produtos nas operações de compra e venda e para a agroindústria contribui para reduzir fraudes no mercado, em função qualidade e do preço.

\section{Considerações Finais}

Levando em consideração a falto de aplicativos destinados a classificação de grãos, torna-se importante o desenvolvimento de um aplicativo que auxilie os produtores nesta atividade, tendo como critério de segurança nas informações 
produzidas e praticidade. Conclui-se, então, que a elaboração dos diagramas de Classe, Caso de Uso, Sequência e Entidade e relacionamento, com informações levantadas por meio dos requisitos, levanto em conta todos os riscos durante a elaboração do projeto, contribuiu com o desenvolvimento do App G-Grãos, com interface simplificada, que agrega 4 tipos de grãos com seus respetivos defeitos leves e graves, grupo, classe e tipo, mostrando ser uma importante ferramenta para o entendimento de diversos fatores em uma classificação de grãos.

Portanto a análise e modelagem tornasse essencial no que se diz respeito ao sucesso do App, de modo que bem modelado, estruturado e testado, garantirá o correto funcionamento, e evitar possíveis erros ou funcionalidade que não atende as necessidades do mercado ou produtor. Como trabalho futuro, pretende-se incrementar novas funcionalidade com base em um novo levantamento de requisitos, e posteriormente implementa-las a fim de ter o feedback de um respectivo grupo de produtores da região de Iporá, Goiás, em que cada um contribui com a expansão do App.

Como estudos futuros, sugere-se implementar incluir novas funcionalidades no App G-Grãos como exportação de dados, tirar fotos dos grãos pela câmera do celular e assim proporcionar recursos para reconhecimento de padrões auxiliando numa tomada de decisão.

\section{Referências}

Abiove - Associação Brasileira das Indústrias de Óleos Vegetais. (2019). Manual de boas práticas de classificação de Soja. https://abiove.org.br/wpcontent/uploads/2019/05/08022018-122719-manual_de_boas_práticas_de_classificacao_de_Soja_05_02_web.compressed.pdf.

Alencar, E. R., Faroni, L. R. D., Filho, A. F. L, Peternelli, L. A. \& Costa, A. R. (2009). Qualidade dos grãos de soja armazenados em diferentes condições. Revista Brasileira de Engenharia Agrícola e Ambiental. 13(5), Campina Grande.

Bastiani, J. A. \& Martins, R. (2018). Diagrama de Ishikawa. [S. 1.]. https://blogdaqualidade.com.br/diagrama-de-ishikawa/.

Brasil. Ministério da Agricultura, Pecuária e Abastecimento (1984). Mapa. Instrução Normativa Mapa $n^{\circ} 268$, de 22 de agosto de 1984. Estabelece o regulamento técnico do Sorgo, definindo o seu padrão oficial de classificação, com os requisitos de identidade e qualidade intrínseca e extrínseca, a amostragem e a marcação ou rotulagem.

Brasil. Ministério da Agricultura, Pecuária e Abastecimento. (2007). Mapa. Instrução Normativa Mapa $n^{\circ} 11$, de 16 de maio de 2007. Estabelece o Regulamento Técnico da Soja, definindo o seu padrão oficial de classificação, com os requisitos de identidade e qualidade intrínseca e extrínseca, a amostragem e a marcação ou rotulagem.

Brasil. Ministério da Agricultura, Pecuária e Abastecimento (2008). Mapa. Instrução Normativa Mapa $n^{\circ} 12$, de 28 de março de 2008. Estabelece o regulamento técnico do Feijão, definindo o seu padrão oficial de classificação, com os requisitos de identidade e qualidade intrínseca e extrínseca, a amostragem e a marcação ou rotulagem.

Brasil. Ministério da Agricultura, Pecuária e Abastecimento (2011). Mapa. Instrução Normativa Mapa $n^{\circ} 60$, de 22 de dezembro de 2011. Estabelece o regulamento técnico do Milho, definindo o seu padrão oficial de classificação, com os requisitos de identidade e qualidade intrínseca e extrínseca, a amostragem e a marcação ou rotulagem.

Chaves, A. M. S. (2017). Técnicas de extração de requisitos. [S. 1.]. https://www.tiespecialistas.com.br/tecnicas-de-extracao-de-requisitos.

Generoso, M. (2019). Banco de dados-Parte 1: Diagrama Entidade x Relacionamento (DER). [S. 1.]. https://medium.com/@mauriciogeneroso/banco-dedados-diagrama-entidade-X-relacionamento-der-5ce497d930db.

Góes, W. M. (2014). Aprendendo UML por meio de estudos de caso. São Paulo: Novatec.

Gonçalves, E. J. T. \& Cortés, M. I. (2015). Análise e projeto de sistemas. 3, Fortaleza, CE Eduece.

Guedes, G. T. A. (2018). UML 2: Uma abordagem prática. 3, São Paulo: Novatec.

Justo, A. S. (2018). In: EAP (Estrutura Analítica do Projeto): o que é, como fazer e qual a diferença entre EAP e Cronograma. https://www.euax.com.br/2018/12/eap-estrutura-analitica-projeto/.

Knabben, C. C. \& Costa, J. S. (2012). Embrapa. Manual de Classificação do Feijão. Instrução Normativa $N^{\circ} 12$, de 28 de março de 2008.

Pereira, A. S. et al. (2018). Metodologia da pesquisa científica. [e-book]. Santa Maria. Ed. UAB/NTE/UFSM. https://repositorio.ufsm.br/bitstream/handle/1/15824/Lic_Computacao_Metodologia-Pesquisa-Cientifica.pdf?sequence=1.

Sampaio, V. A. M. (2015). Classificação de Grãos passo a passo soja, milho, feijão. Cartilha de Classificação de Grãos, [s. 1.]. https://aiba.org.br/wpcontent/uploads/2017/01/Cartilha-Classificacao-de-Graos-Versao-Digital.pdf.

Serviço Nacional de Aprendizagem Rural - Senar (2017). Grãos: classificação de soja e milho. Coleção SENAR - Brasília: 152p., 
Research, Society and Development, v. 10, n. 5, e34310515040, 2021

(CC BY 4.0) | ISSN 2525-3409 | DOI: http://dx.doi.org/10.33448/rsd-v10i5.15040

Silvestri, G. (2017). Prototipação e a criação de produtos que resolvem problemas. [S. 1.]. https://uxdesign.blog.br/o-objetivo-de-um-prot\%C3\%B3tipo\%C3\%A9-criar-uma-representa\%C3\%A7\%C3\%A3o-semi-real\%C3\%ADstica-de-algo-que-seja-poss\%C3\%ADvel-e0445d85ca93.

Silvestre, P. (2017). Empresas erram classificação da soja e revoltam produtores. https://www.canalrural.com.br/sites-e-especiais/projeto-soja-brasil/empresastem-errado-na-hora-de-classificar-a-soja/. 